\title{
Filosofía y dialéctica en Aristóteles
}

\author{
Julio César Krüger Castro \\ Departamento Académico de Filosofía
}

S e ve en Aristóteles al fundador de la lógica formal y se estudia su teoría

3 sobre el silogismo demostrativo, su teoría de la ciencia, su investigación sobre el tiempo, el movimiento, el lugar, su lógica, su física y su metafísica, sus categorías, sus conceptos de sustancia, materia y forma, potencia y acto, sus teorías sobre el primer motor, su ética y su poética, sus obras biológicas.

Pero entre su Analítica y su Metafísica, están los Tópicos y las Refutaciones Sofísticas y la Retórica. En estos fibros pero especialmente los Tópicos -su tratado sobre la dialéctica- encontramos lo que dice Aristóteles sobre la dialéctica que no es precisamente la de Platón, su maestro, sino la dialéctica practicada con virtuosismo por los sofistas. Sobre esta dialéctica hay referencia en otros libros de Aristóteles, como la Retórica y aún la Etica a Nicómaco y Las partes de los animales, pero también en los Analiticos y en la Metafísica.

\section{Biblioteca de Letras}

Platón no aparecęcomosu predecesor sino los sofistas, a quienes toma en serio. Un estudio de estos textos y de la Metafisica permite ver la importancia de esta dialéctica que si bien diferencia y hasta opone a la filosofía, presenta como un acto útil cuyas funciones son el ejercicio mental, el capacitar para examinar el pro y contra y argumentar a favor y en contra de cualquier cosa, $y$ es un proceso de crítica que lleva al camino que conduce a la investigación de los principios. Dice Aristóteles que es un método de investigación de los principios y a ella corresponde propiamente, o más propiamente el examen.

Siendo la refutación y la aporética partes de la dialéctica, como señala Aristóteles, se puede apreciar la importancia de la dialéctica en la investigación filosófica de Aristóteles en la cual no recurre a la demostración silogística, y quien dice que la dialéctica es el método de investigación de los principios de toda ciencia y un procedimiento crítico que lleva al camino de toda investigación; siendo entonces, el método de la filosofía. 
Pero como según Aristóteles la dialéctica parte de premisas probables, algunos autores han llegado a plantear que hay una opinión peyorativa de la dialéctica según Aristóteles, como una lógica menor y vacía, opuesta al rigor de la demostración silogística o al silogismo demostrativo, científico.

Si bien algunos textos de Aristóteles dan la impresión de que la dialéctica queda relegada en relación con la dialéctica platónica, a simple lógica de la opinión y de lo probable, no es así. Si bien dice Aristóteles que la dialéctica parte de premisas probables, es decir, admitidas generalmente por todos, por la mayoría, o por los más sabios -o por filósofos- a diferencia de la demostración que parte de premisas verdaderas y primarias, resulta que la dialéctica es menos y al mismo tiempo más que la demostración pues 1) las premisas son principios, y estos a) son indemostrables y además las ciencias no se ocupan-no pueden ocuparse de ellos-y b) la dialéctica es la encargada de investigar los principios, y en este sentido coincide con la filosofía, aunque Aristóteles diga que ésta se ocupa de las cosas, por sí mismas, por la yerdad, y la dialéctica está en relación con otra cosa y no le interesa la verdad, sino persuadir y seducir.

Pero cuando Aristóteles hace investigación metafísica u ontológica realiza en realidad una investigación aporética, dialéctica, pues no puede haber demostración cuando se trata del ser en tanto ser, y de hecho no encontramos razonamientos silogísticos demostrativos en sus obras especulativas, siendo la aporética o aporemática; 'el métode de Aristóteles, es decir, el método dialéctico que cobra toda su fuerza y valor cuando la intuición y la demostración fallan y queda la indagación, la investigación problemática, la dialéctica en el sentido en que la entiende Aristóteles.

La dialéctica es el arte de interrogar; instrumento universal de examen, es de su esencia plantear cuestiones más que responderlas, y la palabra humana sobre el ser es dialéctica, siendo la realidad ontológica, dialéctica.

La metafísica es la ciencia buscada pero no hay ciencia del ser en tanto ser, pues el ser no es una esencia y no puede ser demostrado.

La investigación de la filosofía, dicho de otro modo, la dialéctica, devino, según P. Aubenque, en filosofía de la investigación.

Escribe Aubenque: "Cuando habla de dialéctica, Aristóteles no parece querer introducir una concepción nueva, ni referirse al uso platónico, sino simple- 
mente sistematizar una práctica, en alguna forma popular y que él juzga suficientemente conocida para que sea superfluo definirla. Se encuentra en Aristóteles una teoría de la dialéctica, pero exactamente como se encuentra en él una teoría sobre la retórica, es decir una reflexión nueva sobre un arte antiguo. La dialéctica existe, tiene sus procedimientos, sus tradiciones, sus maestros, su prestigio propio. Aristóteles no pretende sino sistematizar el uso y esclarecer su significado y no propone, con ella, un método inédito de pensamiento o de investigación". ${ }^{1}$

Según Aristóteles, sobre la dialéctica no existía nada en absoluto. No se puede decir que haya sido elaborada en parte, y en parte, no. "De nuestra investigación actual, sin embargo no es verdad decir que haya sido ya elaborada en parte sí y en parte no; no existía en absoluto"2.

No existía nada elaborado sobre la dialéctica. Sobre el razonamiento, dice Aristóteles que no hay ninguna obra antigua sino que estuvieron largo tiempo trabajando en búsqueda y tentativas diversas, a diferencia de lo que pasaba con la retórica sobre la cual existía ya mucho material enunciado en el pasado. "Así también, en el caso de la retórica, existía ya mucho material enunciado en el pasado, mientras que, por lo que se refiere al razonamiento, no tenemos ninguna obra antigua que citar, sino que estuvieron largo trabajando en búsquedas y tentativas diversas"3.

Sobre la dialécticå afirma-Aristóteles que no existía nada elaborado, es decir "que no había obra teórica sobre esta cuestión....

Dice Aubenque, que la sofística ya existía y que los sofistas practicaban la dialéctica pero que -citando a Aristóteles- "ellos enseñaban no al arte sino los resultados del arte. Su práctica se limitaba pues a recetas empíricas y no proponían el método"s.

Si los sofistas practicaban la dialéctica pero no proponían el método ¿quién lo hizo?, Aubenque se contradice pues, cuando afirma que Aristóteles no propuso un método inédito de pensamiento o de investigación -lo cual es cierto en lo

\footnotetext{
' P. Aubenque Le probleme de l'tre chez Aristote - Ensayo sobre la problemática Aristotélica, P.V.F. Paris 1966. $2^{2}$ edición revisada, p. 254.

2 Argumentos sofísticos 183 b. Traducción Samaranch.

3 Ibid., p. 184 a.

4 Aubenque, op. cit. p. 254.

s Ibid p. 252 cita 184 a2.
} 
que se refiere al pensamiento pero inexacto cuando se refiere al método de investigación-y ahora afirma que los sofistas que según él son los predecesores de la dialéctica a los cuales considera Aristóteles como los dialécticos, practicaban la dialéctica pero no proponían el método, como dice Aristóteles, quien afirma que ellos "concebían que podrían disciplinar y educar a sus discípulos enseñándoles no un arte, sino los resultados de un arte...".

Dice Aubenque que este pasaje con el que cierra Aristóteles el Organon tiene un doble interés histórico "Muestra en primer lugar que Aristóteles no coloca a Platón entre sus predecesores sobre esta cuestión y que no tiene en cuenta en absoluto su especulación sobre la dialéctica, estimando sin duda que no aporta ninguna claridad particular sobre el arte que lleva este nombre. Muestra también que Aristóteles considera a los sofistas como los dialécticos, con la sola reserva de que su práctica de este arte es espontánea, empírica, y en absoluto reflexiva. Aristóteles se considera pues como el fundador de la teoría de la dialéctica, igual que asimismo después se vanagloria de haber inaugurado la teoría del razonamiento".

Sobre la dialéctica hay una experiencia sobre la cual el teórico puede reflexionar: la de los sofistas. "En el momento mismo -escribe Aubenque- en que se presenta como una novedad radical, la teoría aristotélica de la dialéctica, se refiere a la práctica sofística de este arte.

En el Libro A de la Metafisica Segúm Aubenque, "parece hacer gloria de Platón de haber descubierto la dialéctica". Oponiéndolo a los pitagóricos, dice: "sus predecesores no tuvieron ninguna parte en la dialéctica" ( $\delta 1 \alpha \lambda \varepsilon \kappa \tau \iota \chi \hat{\eta} \varsigma$ òv $\mu \varepsilon \tau \varepsilon \hat{\imath} \chi O v)^{7}$.

Sobre este texto de la Metafísica escribe Aubenque: "En cuanto al texto del Libro A, el se remonta a un periodo donde la pertenencia de Aristóteles a la escuela platónica podía conducirlo a exagerar la originalidad de su maestro. De otra parte, Aristóteles, exponiendo a Platón está tentado a tomar la dialéctica en su sentido platónico, y, en este sentido es claro que los predecesores de Platón la hayan ignorado..."

\footnotetext{
* Argumentos sofísticos, 184 a, traducción de Francisco de P. Samaranch.

7 Ibid., p. 255, nota 3 de la página anterior. La cita es de Aubenque (A6, 987 b 32) P. Samaranch traduce: "sus predecesores no conocieron la dialéctica" (Met 988a).

Ibid., p. 255.
} 
La cita completa es así: "el que Platón, a diferencia de los pitagóricos colocara la misma unidad y los números fuera de lo seres sensibles y que llegara a la introducción de las ideas en su explicación, se debe al examen profundo a que sometió las cosas en sus razonamientos, pues hay que tener en cuenta que los que le precedieron no conocían la dialéctica". (O no tuvieron ninguna parte en la dialéctica).

Livio Sichirollo en su libro Dialéctica repite casi literalmente lo que afirma Aubenque. "En realidad, en virtud de los resultados de la crítica evolutiva, Aristóteles escribe Met. I. 6 en un período en el que presenta la tendencia a exagerar la originalidad de su maestro y por tanto, expresa un juicio sobre el cual más tarde reflexiona". Aubenque es más cauto. Dice: "en cuanto al texto del Libro A, el se remonta a un periodo donde la pertenencia de Aristóteles a la escuela podría conducirlo a exagerar la originalidad de su maestro".

Sobre esto hay que decir contra Aubenque que en ese Libro habla Aristóteles de las ideas número de Platóny critica fuertemente la teoría de las Ideas de Platón. Se podría decir entoncés que la proximidad a su maestro podría haberle conducido a criticarlo fuertemente.

Queda en pie el problema: que Platón colocara la misma unidad y los números fuera de los seres sensibles y que llegara a la introducción de las ideas en su explicación "sejdebe âlexamen profuñndo a que sometió las cosas en sus razonamientos, pues hay que tener en cuenta que los que le precedieron no conocían la dialéctica"

La dialéctica tendría entonces en Platón la virtud de conducirle al examen profundo de las cosas en sus razonamientos ¿Por qué entonces no menciona Aristóteles a Platón entre sus predecesores?

En el Libro XIII, Cap. 4 1078b de la Metafísica donde critica también la teoría de las Ideas, escribe Aristóteles:

"La dialéctica no tenía aún entonces un desarrollo suficiente como para poder razonar sobre los contrarios, prescindiendo de la esencia, y para determinar si es una misma ciencia la que trata de los contrarios...".

\footnotetext{
${ }^{9}$ Livio Sichirollo, Dialéctica. Editorial Labor S. A. Barcelona, 1976, p. 53.
} 
Este es un texto que viene inmediatamente después de decir que Sócrates "intentaba razonar silogísticamente las cosas, y el principio de los silogismos es la esencia, la esencia misma de las cosas" (Ibíd., 1078b).

Parece que Aristóteles teoriza sobre la dialéctica que practicaban los sofistas y que cuando habla de la dialéctica y de los dialécticos no se refiere a Platón aunque este conociera la dialéctica y no los pitagóricos. Conocer la dialéctica no quiere decir que Platón fuera su fundador, pues ya existía, según Aristóteles antes de Sócrates, aunque en su tiempo, estaba insuficientemente elaborada. En todo caso, la dialéctica platónica no es una reflexión sobre este arte sino como afirma Aubenque "una transposición filosófica" de ese arte o un uso de este arte, pues sometió las cosas en su razonamiento a un examen profundo, y como dice Aristóteles, a la dialéctica pertenece propiamente el examen.

Aristóteles no da una definición global, ni unívoca de la dialéctica, señala Aubenque $^{10}$ "Y si le asigna varias funciones, se preocupa poco de manifestar la ligazón que las une, como si se refíriera menos a la unidad racional de un concepto que a la unidad linguística de un uso"

No es sino incidentalmente y en raros pasajes que él recuerda que la dialéctica es "el arte de interrogar ( "el hombre capaz de formular las proposiciones y las objeciones" (Ibid., p. 255). Las citas de Aubengue remitena: 1) Ref Sopht 11al 172a18 y 2) Tópicos VIII, $14,164 \mathrm{~B} 3$.

\section{"Jorge Puccinelli Converso"}

Se encuentra también en Aristóteles el sentido que será predominante en el Liceo y en la Nueva Academia "según el cual la dialéctica es el arte de sostener igualmente tanto el pro que el contra sobre una tesis dada" " que es propiamente lo que hacían y sobre lo que se jactaban los sofistas y que Hegel les atribuye como hombres cultos y maestros de cultura del pueblo griego. Dice Aubenque que "él atribuye, en efecto, a la dialéctica el privilegio, que comparte con la retórica, de poder concluir los contrarios" ${ }^{12}$. (Rhet $\mathrm{I}, 1,1355$ a 34) y recuerda que Cicerón alababa a Aristóteles "por haber inaugurado este método de disertación por tesis y antítesis"13.

\footnotetext{
${ }^{10}$ Ibid., p. 253.

"Ibid.. p. 255.

${ }^{12}$ Ibid., p. 255

${ }^{13}$ Ibid., p. 255-256,
} 
En los Tópicos VIII, 163b dice Aristóteles:

"Siempre, al estudiar una proposición cualquiera, hay que tener la mira puesta en un forma de argumento tanto a favor como en contra y al encontrarla, hay que buscar su solución en seguida, porque de esta manera se advertirá inmediatamente que uno se ha ejercitado al mismo tiempo tanto en la forma de proponer cuestiones como en la de responder a ellas"14.

Aubenque traduce así:

"En relación con toda tesis, es necesaria ponerse en busca de argumentos a la vez pro y contra, y una vez que son encontrados, buscar igualmente cómo se les puede refutar, pues de esta manera, se encontrará que se está al mismo tiempo ejercitando tanto a plantear las cuestiones como a responderlas ${ }^{15}$ (Top. VIII, 14, 163a 36-b3).

Esta recomendación de Aristóteles es una invocación a usar la dialéctica, y está de acuerdo con uno de los tres fines que asigna a la dialéctica en los Tópicos (Libros I, Cap 2, 100b). Argumentar el pro y el contra de una cuestión, y buscar cómo se puede refutar, es propio de la dialéctica y de lo que hacían los sofistas, predecesores de Aristóteles en cuanto a la dialéctica, y como hemos mencionado, maestros de cultura del pueblo griego, según Hegel, precisamente por enseñar a defender el pro y centra sobre cualquier tema.

La relación de Aristóteles con los sofistas, si bien lejos ya de la primera generación (no estuvo en contacto con los sofistas del siglo V: Protágoras, Gorgias, Pródico, Hippias), los tomó en serio -como sostiene Aubenque- más que Platón quien, sin embargo se ocupa constantemente de ellos en gran parte de su obra y reiteradamente, aunque burlándose, ridiculizándolos, caricaturizándolos revelando con ello y reflejando su importancia y el problema que le planteaban: el relativismo.

Desde el Eutidemo hasta el Sofista, pasando por el Protágoras y el Gorgias, por ejemplo, siempre los sofistas. Las burlas y sarcasmos en el Eutidemo y la ridiculización de algunos argumentos sofísticos, no impiden volver a encontrar estos argumentos tomados en serio en el Parménides -como observa Jean Wahl-

\footnotetext{
${ }^{14}$ Traducción de P. de Samaranch, op. cit.

15 Ibid., p. 258.
} 
y sus definiciones del sofista, cada vez más tendenciosas y denigrantes del sofista, resultan caracterizando finalmente a Sócrates. Termina hablando de una "sofística superior" que no sería la de los sofistas ¿Y Aristóteles?

"No es sin duda exagerado -escribe Aubenque-decir que la especulación de Aristóteles ha tenido por objeto responder a los sofistas; la polémica contra los sofistas está presente, por doquier en su obra, no solamente en sus escritos lógicos, sino también en la Metafísica e igualmente en la Fisica y ella se deja adivinar en los numerosos pasajes donde la sofística no está considerada expresamente..."

Aubenque llega a sostener no sólo la importancia que Aristóteles le atribuye a la sofística sino inclusive en la constitución de su filosofía. "Al ver la insistencia con la que Aristóteles -escribe Aubenque-vuelve sobre los argumentos que él ha aparentemente ya ha refutado y la pasión que pone en combatir a los filósofos que hacen profesión de despreciar, se presenta la importancia real, aunque inconfesada, de la corriente de pensamiente sofístico en la constitución de su filosofía..."17.

En cambio, la relación de Aristóteles con Platón es distinta. Aristóteles critica a Platón con mucha seguridad y frialdad, y al parecer definitivamente "Muy diferente son sus relaciones con el platonismo: la polémica anti-platónica es más netamente cirçnspcrita yeeszonducidatconsuna seguridad y una satisfacción de sí que da lugara pensar que Aristóteles está bien cerca de considerar su crítica como definitiva..."18, escribe Aubenque.

Al contrario de lo que pasa con Platón "las aporías suscitadas por los sofistas renacen apenas resueltas; se imponen como una obsesión y suscitan ese "asombro", siempre renovado que permanece, para Aristóteles como para Platón, siendo el punto de partida de la ciencia y de la filosofía"19.

Platón dice en el Sofista (231a) que el filósofo y el sofista se parecen como el perro y el lobo. La intención no apunta al parecido sino a marcar la diferencia, pero domesticado o salvaje, manso o feroz, ¿el filósofo preferiría ser comparado al perro?

\footnotetext{
${ }^{16}$ Ibid.. p. 94.

1'Ibid.. p. 94.

${ }^{18}$ Ibid., p. 94.

${ }^{19}$ Tbid., p. 94.
} 
Los textos de Aristóteles, de la Metafisica y las Refutaciones Sofísticas parecen alejar al filósofo lo más posible de la sofística y descalificarla totalmente. La sofística no es finalmente para Aristóteles, una filosofía entre otras -como dice Aubenque- "Ella es, en un sentido, mucho menos que eso porque el sofista no es filósofo y se contenta con revestir la misma apariencia que el filósofo": su sabiduría no es más que "aparente y sin realidad". Pero si la sofística no es una filosofía, ella es "las apariencias de filosofía" y por ello "el género de realidad donde ella se mueve... es la misma que para la filosofía". Finalmente, lo que diferencia al sofista del filósofo es menos la naturaleza misma de los problemas

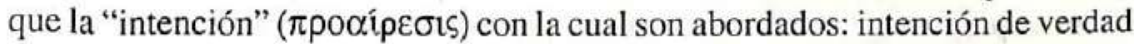
de un lado, búsqueda de un beneficio del otro. ${ }^{20}$

(Citas: Met. t, 2, 1004b, 17, 26, 19, 24. Ver también: Ref. Soph 1, 165a 20; 11, 171b, 27, 33).

Comentando esta cita, Aubenque afirma que esta última consideración parece descalificar a la sofística pero "Ella no la hace sino más temible: es en el fondo su indiferencia en relación a la verdad lo que ha hecho a los sofistas los fundadores de la dialéctica, es decir de un arte que enseña a hacer igualmente verosímil el pro y el contra sobre un mismo problema"21.

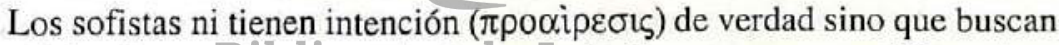
el beneficio. De esoßiempre selestha acusado. Esta es una gran diferencia y hasta oposición con el filósefo Les sefistas notienen nada de filósofos. Aubenque repara sutilmente en que precisamente esta indiferencia con relación a la verdad es la que ha hecho de los sofistas, los fundadores de la dialéctica, un arte que enseña a hacer igualmente verosímil el pro y el contra sobre un mismo problema. Esto, sin embargo extiende la descalificación a la dialéctica; a ella se extiende la acusación de apariencia, engaño y falsedad.

Es precisamente porque no tenían ninguna preocupación por la verdad por lo que los sofistas se centraron en la eficacia del discurso para trasmutar lo falso en verdadero, por lo menos en verosímil 22 .

Pero el filósofo no puede ignorar al sofista "porque lo propio de las tesis sofísticas -escribe Aubenque- es precisamente presentarse como verdaderas,

\footnotetext{
${ }^{20} \mathrm{P}$. Aubenque op. cit. pp. 94-95.

${ }^{21}$ Ibid., p. 95 .

${ }^{22}$ P. Aubenque op. cit. p. 98.
} 
es decir, por filosóficas. Pero la fuerza del sofista es entonces imponer su propio terreno -el del discurso- a su adversario...."23.

A los discursos no se puede responder que por discursos y a su dificultad por otra dificultad de la misma naturaleza. Es pues necesario aceptar el terreno que nos imponen los sofistas; no hacen como Platón que los ridiculiza como en el Eutidemo o más frecuentemente se ingenia para ponerlos en contradicción, forzándolos a admitir que ignoraban en sus diálogos lo que ellos pretendían no ignorar o respondiendo con un mito en el Menón pero hay que "retornar contra ellos sus propias armas, es la refutación, procedimiento puesto a punto por los sofistas y al cual consagró él mismo en tratado..."24.

Con respecto a las Refutaciones Sofísticas, escribe el notable estudioso francés: "Se sabe que no se trata en este tratado, contrariamente a un contrasentido frecuente, de refutar los sofismas, sino de estudiar este modo de razonamiento sofístico que es la refutación; más precisamente, de sustituir la refutación aparente practicada por los sofistas, por la refutación real'2s.

Afirma Aubenque que la mayoría, o al menos los más temibles de los argumentos sofísticos se apoyan en la pluralidad de las significaciones, y el paralogismo, en sentido estricto, consiste, como señala Aubenque, en tomar la misma palabra en acepciones diferentes en el curso de un mismo razonamiento. Así, distinguir las significadiones mülttipłes de las palabras será, a la inversa, la primera tarea "de quien (quiere đenunciarllàs dusiones sofísticas. En efecto -escribe Aubenque- sólo la distinción de las significaciones nos permite discernir, detrás de las palabras pronunciadas por el interlocutor, las intenciones que lo animan en el momento en que la pronuncia..."26.

Así afirma Aubenque que la distinción de las significaciones "será por tanto el método de refutación de los sofismas".

De este modo "refuta" a los que niegan el principio de contradicción. Tal es el principio de la "refutación" de Aristóteles, afirma Aubenque. El problema, sin embargo, no acaba aquí: Una cosa ¿no puede tener varios significados?. Aristóteles responde que "si una misma cosa pudiera presentar una pluralidad

\footnotetext{
${ }^{23}$ Ibid., p. 95.

${ }^{24}$ Ibid., p. 97.

${ }^{25}$ Ibid., p. 97 nota 31 .

${ }^{26}$ Ibid., p. 120.
} 
indefinida de significaciones, todo lenguaje sería imposible, puesto que cada palabra no remitiría a una intención, sino a una infinidad de intenciones posibles", "no significar una cosa, una, hemos visto, es no significar nada absolutamente"27.

Ahora bien, ¿qué es lo que garantiza que tal palabra conserve una significación una? -pregunta Aubenque-. Su respuesta es: "Esta unidad objetiva, que funda la unidad de la significación de las palabras, es lo que Aristóteles llama la

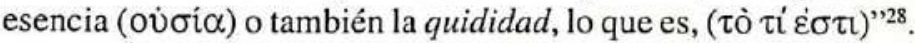

De aquí deriva Aubenque que "La teoría aristotélica del lenguaje presupone pues una ontología. Pero inversamente, la ontología no puede hacer abstracción del lenguaje"29.

Pero un texto capital del libro IV de la Metafísica trata "sin ambigüedad" dice Aubenque de la problemática referente a que las categorías designan de maneras múltiples lo que el ser significa; los diferentes discursos sobre el ente ( $\tau o ̀$ óv) proporcionan aquí el hilo director đe la búsqueda. "De esta problemática testimonia sin ambigüedad un texto capital del libro t: después de haber recordado que el ser, o más bien el ente ( $\tau$ ò óv), "se dice en muchos sentidos", Aristóteles se pregunta por qué los díferentes entes se dicen ser, lo que hace el ser de los entes; se discierne entonces que la respuesta a esta cuestión no es una: entre las cosas, "las unas son dichas los seres (ŏv $\tau \alpha$ ), porque son las esencias ..., las otras porque son las afecciones de la esenciag.s las otras porque son las destrucciones o privaciones $e$ las cualidades olos agentes o los generadores de la esencia" ${ }^{30}(\tau, 2,1003$, b5 ss.).

Si nos es permitido reconocer en estas fórmulas lo que Aristóteles llaman en otra parte las categorías, ellas aparecerán como otras tantas respuestas a la cuestión: ¿En qué sentido decimos del ente que es?, plantea Aubenque: "La pluralidad de las categorías -escribe-expresarían entonces la imposibilidad en que se encuentra la filosofía de dar una respuesta única a esta cuestión; porque

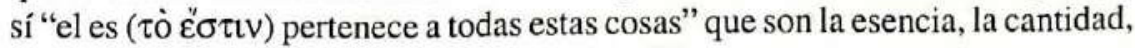
las cualidades etc., no es de la misma manera" ${ }^{\text {. }}$.

\footnotetext{
${ }^{27}$ Ibid., p. 127 (la cita es de t; 4, 1006, b7).

${ }^{28}$ Ibid., p. 127.

${ }^{29}$ Ibid., p. 133.

${ }^{30} \mathrm{P}$. Aubenque op. cit. p. 184.

${ }^{31}$ Ibid., p. 184.
} 
El objeto final de la cuestión fundamental que es el objeto pasado, presente y eterno de su dificultad y su investigación de Aristóteles: Que es el ente ( $\tau o ̀$ óv) es ¿Cómo el significa?. "En este sentido, -escribe Aubenque- las categorías son menos las divisiones del ente que las modalidades ( $\pi \tau \omega \sigma \varepsilon 1 \varsigma)$ según las cuales el ser significa al ente, Ellas no responden a la cuestión: ¿En cuantas partes se divide el ente? sino a esta otra: ¿Cómo el ser significa?”32.

Sobre $\pi \tau \hat{\omega} \sigma \iota \varsigma$ cabe la aclaración de Aubenque " $\pi \tau \hat{\omega} \sigma \iota \zeta$ designa de una manera general toda modificación de la expresión verbal que se refiere no al sentido sino a la manera de significar. Este es el caso de las flexiones de los sustantivos y de los verbos $\pi \tau \hat{\omega} \sigma$ เ $\varsigma$ es empleado para designar las categorías en N, 2, 1089 a 27. Es el término más sutil que Aristóteles emplea para designarlas,

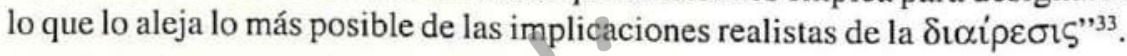

La cuestión ¿Qué es el ente? No podría ser entendida por Aristóteles sino en términos de esencia o-lo que viene a ser lo mismo- en términos de significación. "Pero aquí -observa Aubenque-se choca con la pluralidad ineductible de significaciones del ser: el ser del ente no tiene un sentido, sino varios sentidos, lo que viene a decir que el en tanto que ser no es una esencia. A la fórmula frecuentemente repetida: "El ente se dice en muchos sentidos", responde un

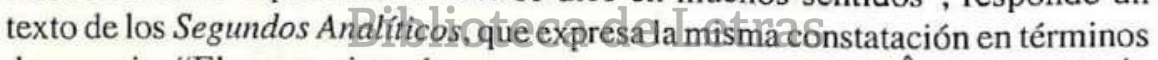

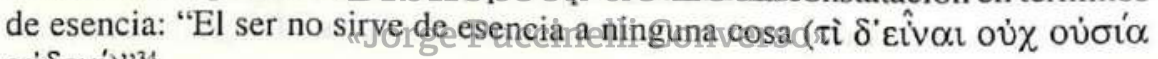

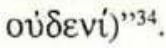

Aunque el ser se dice en múltiples sentidos, Aristóteles no parece haber puesto en duda la posibilidad de un discurso coherente sobre el ser cuando al comienzo del libro IV de la Metafísica afirma sin vacilar la existencia de una ciencia del ser en tanto $\operatorname{ser}(\tau, 1,1003$ a 21$)$, dice Aubenque quien señala que "sería fácil verificar que los otros textos invocados por los comentadores a favor de una pretendida analogía del ser en Aristóteles: 1) no conciernen directamente al ser; 2) Presuponen, bien lejos que contribuyen a reducir la pluralidad radical de las categorías..." 35 .

\footnotetext{
${ }^{32}$ Ibid., p. 184.

${ }^{33}$ Ibid., p. 184, nota 3.

${ }^{34}$ Ibid., pp. 185-186.

${ }^{35}$ Ibid., p. 206 , nota 1.
} 
Aubenque dice que "Uno se podría asombrar de esta aparente contradicción entre la afirmación de una pluralidad radical de significaciones y la confianza en un discurso unificado, o al menos unificable, sobre el ser, si no se hubiera aprendido a distinguir entre las declaraciones pragmáticas de Aristóteles y sus realizaciones efectivas" ${ }^{\prime 36}$.

¿Ha tenido éxito Aristóteles en constituir una ciencia del ser en tanto que es, en el sentido en que define en los Segundos Analíticos la ciencia demostrativa?. Dice Aubenque que la seguridad aparente de Aristóteles aún si durante siglos ha reducido a los comentadores "no nos debe dispensar de plantear la cuestión. Pero la contradicción no es solamente entre las intenciones y el sistema. Ella aparece ya al nivel de declaraciones de principio; todo sucede como si Aristóteles, en el momento mismo en que se presenta como el fundador de la ciencia del ser en tanto ser, multiplicara los argumentos para demostrar la imposibilidad" ${ }^{37}$.

Sostiene Aubenque que la ciencia aparece en Aristóteles "como un límite entre la dispersión de las sensaciones particulares y la incertidumbre de las generalidades retóricas. Por ello se explica la coexistencia, en los textos de Aristóteles, de dos series de afirmaciones que podrían parecer contradictorias: Toda ciencia es ciencia de lo universal, y sin embargo, no hay ciencia de lo universal, o aún: toda ciencia es particular..." ${ }^{38}$.

Contra los sofistas se dirige un pasaje de las Refutaciones Sofisticas donde Aristóteles muestra que es én vano hacer un recenso de los lugares de todas las refutaciones posibles porque, para hace eso, "sería necesario poseer la ciencia

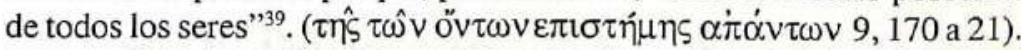

Comentando este texto, escribe Aubenque: "Aristóteles parece querer mostrar en primer lugar por ello que una técnica universal de la refutación es humanamente imposible de adquirir, si al menos se admite que el refutador debe cada vez ser tan competente que su adversario: geómetra si refuta a un geómetra, médico si refuta a un médico, etc..." ${ }^{40}$.

\footnotetext{
${ }^{36}$ Ibid., p. 206.

${ }^{37}$ Ibid., p. 207.

${ }^{33}$ Ibid., p. 211.

${ }^{39}$ Ibid., p. 210.

${ }^{40}$ Ibid., p. 212.
} 
$\mathrm{Al}$ comienzo de sus obras biológicas. Aristóteles nos advertirá "que es necesario elegir entre la "cultura general" y la ciencia de la cosa" (Part anim. I, 1, 63 a 3,7) "No es una de las menores paradojas de Aristóteles la de haber demostrado largamente la imposibilidad de la ciencia a la cual ha ligado su nombre"4l.

Se dirá que esta paradoja se debe a una inadvertencia de Aristóteles o al estado inacabado de su trabajo "Pero sería muy fácil atribuir esta paradoja a una inadvertencia de nuestro autor o, como se ha hecho frecuentemente explicar sus aparentes y muy numerosas contradicciones por el estado inacabado de sus trabajos" 42 .

Nos parece exacta la observación de Aubenque:

"La dificultad (de la cual la contradicción es la forma, podríamos decir, cristalizada) es en Aristóteles el momento esencial de la investigación filosófica: ella es aporia, es decir, interrupción de la marcha del asunto, y su solución es la condición de un nuevo punto de partida. Porque la buena marcha ( $\varepsilon v \pi \circ \rho i \alpha)$ futura se confunde con la solución de las aporías precedentes". Ahora bien, resolver una aporía no es eludirla, es desarrollarla $(\delta \imath \alpha \pi \circ \rho \hat{\eta} \sigma \alpha \imath)$, no pasar de costado, sino hundirse en ella y recorrerla de parte en parte $(\delta \mathrm{t} \alpha)^{43}$.

Es digna de tener en cuenta la observación de Aubenque quien escribe:

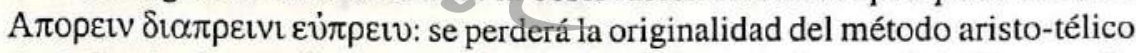
desdeñando el segundo momento, que es̄. a decir verdad, esencial. "Buscar sin

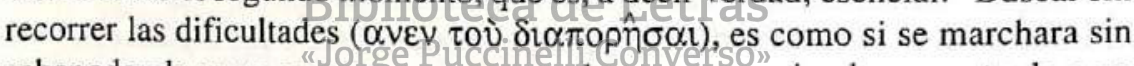
saber adonde se va, es exponerse a no poder reconocer si se ha encontrado o no lo que se buscaba" 44 .

Hace recordar esto último, la aporía planteada por Menón: la investigación es inútil si se conoce completamente lo que se investiga y si se encontrara, no se sabría si lo encontrado es lo que se buscaba. La salida de Platón es la teoría de la reminiscencia con la cual no está de acuerdo Aristóteles.

Cabe citar todo el pasaje del texto del libro III, cap, 1 de la Metafisica para ver el sentido del método aporético o aporemático de Aristóteles y su importancia para la filosofía.

\footnotetext{
${ }^{41}$ Ibid., p. 221.

${ }^{42}$ Ibid., p. 221.

${ }^{43}$ Ibid., p. 221.

${ }^{44}$ Ibid., pp. 221-222.
} 
"Para que el estudio de la ciencia que vamos a comenzar sea eficaz, es necesario, en primer lugar, recorrer todas aquellas cuestiones de que inicialmente habemos de dudar. Estas cuestiones son aquellas sobre las que los filósofos han emitido opiniones contradictorias y todas aquellas que ellos hayan preterido o los puntos que en ellas hayan podido dejar sin aclaración. Es de importancia para todo el que quiera alcanzar una certeza en su investigación saber dudar sensatamente a tiempo. Pues toda interior certeza o carencia de dudas proviene de la solución de lo que antes era objeto de duda..."45.

En este texto se ve la relación entre el método aporético o aporemático y la dialéctica, pues las cuestiones son aquellas sobre las que los filósofos han emitido opiniones contradictorias o las que han dejado sin aclaración. Aristóteles sostiene inclusive que no se puede dar solución a una cosa si se ignora el punto de la dificultad; "pero -continúa Aristóteles- dar solución a una cosa no es posible si se ignora el punto de la dificultad. No se puede desatar un nudo sin conocer cómo está hecho. La duda inquieta del entendimiento es prueba de ello. Porque encuanto duda o vacila es semejante a un ser encadenado, ya que no le es posible avanzar más allá ni de una ni de otra manera. Por esta razón es conyeniente estudiar primero todas las dificultades y en orden a esto y también por esta razón, los que buscan algo sin dudar primero, se asemejan a los que ignoran, al caminar, qué senda deber seguir, y respecto de estas cosas, no pueden llegar a saber si han conseguido lo que inquirirían o no. Påra eistosenefecto, ne existe un fin determinado en su proceso investigadorjol en cambion síl estáclaro para el que antes se ha planteado la duda. Además, es lógicamente necesario que esté más preparado para emitir un juicio o una opinión aquel que, como quien oye a las partes contrarias en un juicio, atiende primero a todas las razones, opuestas de una y otra parte" 46 .

Luego comienza a presentar las dificultades y concluye: "Respecto de estas cuestiones no sólo es difícil hallar la verdad, sino incluso lo es el formular la duda en un razonamiento que tenga rigor" 47 .

La aporía y la diaporía (desarrollo de los argumentos en pro y en contra de los cuales "la igualdad" determina el estado de aporía (Top. VI, 6145 p1, 17)

\footnotetext{
${ }^{45}$ Met. Libro III, Capitulo tercero, 994b-995b, traducción de P. de Samaranch.

${ }^{46}$ Ibid., 995b.

${ }^{47}$ Ibid., 996a.
} 
son procedimientos dialécticos. Aubenque nos remite a los Tópicos VIII, II, 162 a 17; también a I, 2,101 a $35^{48}$.

En los Tópicos VIII, 14, 168 a 36-b3 versión de Aubenque (op. cit., p. 256) dice Aristóteles: Con respecto a toda tesis, es necesario ponerse en busca de argumentos a la vez pro y en contra, $y$, una vez que son encontrados, investigar cómo se les puede refutar, puesto que, de esta manera, se encontrará que se ha ejercitado tanto en plantear las cuestiones como a responderlas.

Dice Aubenque que las aporías en Aristóteles no son como para Platón el signo de una ignorancia de la ontología. "Las aporías megáricas -así como las aporías en general, cuando son fundadas- no son el signo, como lo ha creído Platón, de una ignorancia de la ontología, sino que manifiestan las dificultades que son por sí mismas ontológicas, pues conciernen en primer lugar al discurso humano sobre el ser; es pues sobre su propio terreno que es necesario dedicarse a resolverlas. Es de esta reflexión sobre las aporías que nacerá la ontología aristotélica..."49.

En la Etica a Nicómaco escribe Aristóteles sobre la dificultad o aporía en relación con las que plantean los sofistas:

"Otra dificultad: el razonamiento de los sofistas, llamado razonamiento del que miente. Al querer hacer admitir al auditorio opiniones paradójicas para pasar por talentos hábiles, si lo consignen vienen a parar a un razonamiento que sólo crea dificultades. Pues el uso de da reflèxión queda trabado cuando, por una parte, no se pueden dar más pasos adelante, por la imposibilidad de dar una respuesta al razonamiento...

Como conclusión de este capítulo, pone en relación las dificultades y el descubrimiento de la verdad:

"Tales son, pues, de alguna manera, las dificultades que se nos presentan: es necesario dar solución a algunas de ellas y dejar otras de lado, pues el hallazgo o el descubrimiento de la verdad consiste en solventar las dificultades..."51.

De aquí concluye Aubenque que "se podrá decir que la ciencia aristotélica del ser en tanto ser, no es otra que el sistema general de la solución de las aporías"s2.

\footnotetext{
41 Aubenque op. cit., p. 301, nota 4.

${ }^{49}$ Ibid., pp. 158-159.

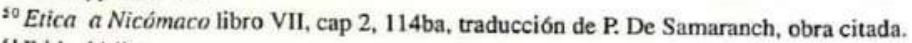

st Ibid., 114ba.

${ }^{52}$ Ibid., p. 159.
} 
La primera fase de los Tópicos comienza con: "El fin de este tratado es encontrar un método gracias al cual podamos razonar ( $\sigma u \lambda \lambda \sigma \gamma l \zeta \varepsilon \sigma \theta \alpha l)$ sobre cualquier problema propuesto partiendo de tesis probables $(\varepsilon \xi \xi \vee \delta \circ \xi \omega \mathrm{\xi}){ }^{\prime \prime 53}$.

Pero después designa como razonamiento ( $\sigma \nu \lambda \lambda \sigma \gamma \imath \sigma \mu o ́ s)$ dialéctico este razonamiento que acaba de definir y que será el objeto de investigación del presente tratado" 54 .

En los Tópicos, la dialéctica se diferencia ("se opone", según Aubenque) del razonamiento demostrativo, o de la "demostración", o de la ciencia por estos dos puntos. "Sobre estos dos puntos señalados por Aristóteles - universalidad de la capacidad dialéctica y probabilidad del punto de partida- la dialéctica se opone a la ciencia, de la cual Aristóteles hace la teoría en los Segundos Analíticos. Mientras que la ciencia se refiere a un género determinado del ser y sobre uno solo..." la dialéctica no se dirige ni a las cosas determinadas de esta manera... ni a un género único.

Mientras que cada ciencia se apoya en los principios que le son propios, la dialéctica intenta demostrar los principios comunes ( $\kappa o \iota v \alpha)$ a todas las ciencias como el principio de contradicción; estos principios son en comunión ( $\varepsilon \sigma \tau$

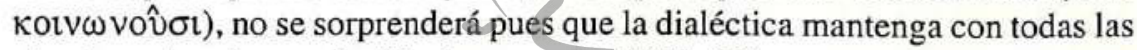
ciencias esta misma relación de comunión" (77a 29).

\section{Biblioteca de Letras}

El segundo carácter la probabilidad de la tesisodialéctica (que se opone a la necesidad de las premisas del silogismo demostrativo) es, según Aubenque "la contrapartida inevitable de su generalidad"55.

La dialéctica parte de premisas probables, es decir de opiniones generalmente admitidas; el razonamiento es una "demostración" cuando las premisas de que parte son verdaderas y primarias, o bien cuando el conocimiento que tenemos de ellas se ha conseguido originariamente en virtud de premisas verdaderas"

Por otra parte, el razonamiento es "dialéctico" sí razona a partir de opiniones generalmente admitidas ${ }^{57}$.

\footnotetext{
${ }^{53}$ Ibid., p. 256, Aubenque cita I, 1, 1009 a 181.

${ }^{54}$ Aubenque op. cit., p. 256. La cita es Top, I, 1, 100a 22.

ss Ibid., p. 258.

${ }^{56}$ Tópicos 100 a Traducción de Samaranch.

${ }^{57}$ Tbid., 100a.
} 
Estas opiniones generalmente admitidas son las de todos los hombres, o la de la mayoría, o de las más sabios; es decir, de los filósofos. Mientras que la “demostración" parte de premisas verdaderas y primarias, la dialéctica parte de premisas probables.

Cabe mencionar aquí lo que dice Aubenque sobre las tesis probables de las cuales parte la dialéctica: se ha sostenido, en verdad que se toma en un sentido restrictivo la expresión ( $\tau \alpha \grave{\alpha} \varepsilon v \delta o \xi \alpha$ ), que nosotros traducimos por tesis probables...

Pero la noción de probabilidad no es por sí misma peyorativa; no lo es si no se refiere a la necesidad de las premisas del silogismo demostrativo, exactamente como la generalidad quizá inevitable del discurso dialéctico no es condenable más que si la compara a la perfecta determinación del dominio de cada ciencia particular. En sí, la probabilidad representa un proceso en relación con la tesis simplemente: la probabilidad no es lo arbitrario y la tesis probable es infinitamente más que la simple hipótesis" ${ }^{58}$.

Las tesis probables no son cualesquiera. Son aquellas que corresponden a las opiniones de todos los hombres o a la mayoría, o a los sabios, y entre estos últimos la de todos, la de la mayor parte, sea en fin de los más notables y de los más reconocidos.

\section{Biblioteca de Letras}

Señala Aubenque que cuande Aristôteles invocada autoridad de los sabios para definir la probabilidad de la tesis dialéctica, no piensa en un carácter intrínseco de la sabiduría sino que sabio es el que es reconocido por todos como tal. Aristóteles, entonces, define la autoridad del sabio por el consentimiento universal, "sustituyendo así -escribe Aubenque- la autoridad de la sabiduría por la sabiduría de la autoridad. Se aprecia por ello tanto el valor como los límites de la probabilidad dialéctica: correlato de los discursos universales en el doble sentido de discursos sobre la totalidad y de discursos admitidos por la universalidad de los hombres, ella es ciertamente inferior a la demostración, pero interviene cada vez que la demostración es imposible, es decir, cada vez que el discurso se universaliza al punto de perder todo punto de apoyo real... ${ }^{59 "}$.

\footnotetext{
5h Ibid., p. 258.

s9 Ibid., p. 259.
} 
Según Aristóteles en los Tópicos, los fines de la dialéctica son tres: El ejercicio o formación del intelecto, las conversaciones o disputas casuales y para las ciencias filosóficas ${ }^{60}$.

La dialéctica dice también Aristóteles es "el arte de interrogar"

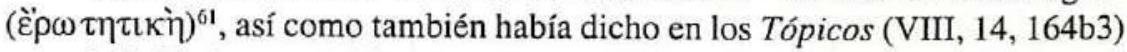
que el dialéctico es "el hombre capaz de formular las proposiciones y las objeciones", y en la Retórica comparte con la retórica el privilegio de "concluir los contrarios"'(Rhet, I, 1, 1355 a 34).

El dialéctico es menos sabio que cultivado. El no sabe nada por si mismo, sino que "repite lo que se dice y es obligado a satisfacerse en la discusión de la aceptación de su interlocutor. Al proceder así, dice Aristóteles, no se está seguro jamás de ir hasta el punto en que la investigación es posible, esto es, hasta la cosa misma, puesto que se detendrá donđe se habrá encontrado no lo verdadero, sino lo que parece verdadero. Ahora bien, la verosimilitud es un criterio de probabilidad, no de verdad... Especialista de generalidades, el dialéctico puede parecer superior a los sabios puesto que su dominio es coextensivo a la totalidad de sus campos particulares; en realidad es inferior a cada uno en su dominio propio. Finalmente, su discurso no obtiene la universalidad que al precio de la vacuidad; se sabe que Aristóteles asocia a menudo las ideas de dialéctica y de generalidad vacía... ${ }^{62 "}$.

"Recíprocamente-escribe Aubenque-reflexibnando en el Organon sobre el procedimiento dialêcticé, Aristételes insistirâ, arspismo tiempo que en las limitaciones de este método, sobre la universalidad de su visión, y por ello estará bien cerca de reconocer al mismo tiempo que su oposición al discurso demostrativo, su extraño parentesco con la investigación ontológica"63.

Donde mejor se esclarecen la función y los límites de la dialéctica según Aristóteles es un De Partibus animalium.

En todo género de especulación y de investigación, lo más banal como la más relevante parece que hay dos clases de actitud; se llamaría bien a la primera

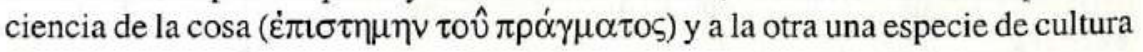

\footnotetext{
${ }^{60}$ Libro primero. Cap. 2, 200b.

${ }^{61}$ Ref. Sof, 11, 172a 18.

${ }^{62} \mathrm{P}$. Aubenque. $\mathrm{M}$ cit. p. $260 \mathrm{~S}$.

${ }^{63}$ Ibid., p. 281.
} 
( $\pi \alpha 1 \delta \varepsilon \iota \alpha \nu \tau \iota \nu \alpha)$. Porque es bien el hecho de un hombre cultivado ser apto de tener un juicio ( $\kappa \rho v \alpha \iota)$ pertinente sobre la manera, correcta o no, según la cual se expresa el que habla. Porque es esta cualidad que pensamos pertenece al hombre dotado de la cultura general ( $\tau \dot{0} v$ ó $\lambda \omega \varsigma \pi \varepsilon \pi \delta$ เ $\delta \varepsilon v \mu \varepsilon v o v$ ) y el resultado de la cultura ( $\tau 0 \pi \varepsilon \pi \alpha \mathrm{l} \delta \varepsilon \hat{v} \sigma \theta \alpha \mathrm{l}$ ) es precisamente esta aptitud. Agregamos, es verdad, que este es, pensamos capaz de juzgar ( $\kappa\llcorner\iota \imath \chi o ́ v)$, el completamente solo, por así decir, de todas las cosas, mientras que el otro no es competente

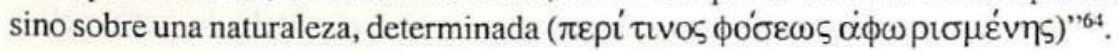

Explicando estos fines, dice Aristóteles; que es útil como ejercicio o formación del entendimiento y resulta evidente a primera vista "El estar en posesión de un plan de investigación nos capacitará para argumentar más fácilmente acerca del tema propuesto." 65

En orden a las conversaciones o disputas casuales "es útil porque una vez hayamos considerado las opiniones sostenidas por la mayoría de la gente, podemos hacerles frente, no apoyândonos en las convicciones de los demás, sino por nuestras propias convicciones, tirando abajo cualquier argumento que nos parezca irrazonablemente sostenido..."

Pero la dialéctica, según Aristóteles: "Es útil para el estudio de las ciencias filosóficas, porque la capacidad de suscitar dificultades profundas en las dos posturas de un tema nos hiará detetectar mấs. fâcilmentel diversos puntos y cuestieneseque surjanl.li" שonverso"

Pero la dialéctica tiene, según Aristóteles, una utilidad ulterior: someter en discusión los principios de la ciencia - lo que es propio de la filosofía- y es un proceso de crítica en el que se halla el camino que lleva a los principios de toda investigación.

"Tiene también - escribe Aristóteles-una utilidad ulterior en relación con las bases de los principios que emplean las diversas ciencias, pues es imposible someterlos a discusión a partir de los mismos principios propios de la ciencia particular de que se trata, supuesto que los principios son lo anterior de todo lo demás; estos deben discutirse a la luz y en virtud de las opiniones generalmente

\footnotetext{
${ }^{64}$ Part Animal, I, 1, 639a 1-1 (trad. La Blond modificado por Aubenque op. cit. p. 282).

${ }^{65}$ Ibid., 100b-101b.

${ }^{60}$ Ibid., $101 \mathrm{~b}$.

${ }^{67}$ Ibid., $101 \mathrm{~b}$.
} 
sostenidas en las cuestiones particulares, y esta tarea corresponde propiamente o más apropiadamente a la dialéctica, en efecto, es un proceso de crítica en que se halla el camino que lleva a los principios de toda investigación"68.

Hay sin embargo otros textos en que Aristóteles aleja, diferencia y hasta opone, dialéctica a filosofía.

En primer lugar en el mismo tratado sobre la dialéctica, escribiendo acerca de las proposiciones y los problemas y su división, dice: "Si obramos con pretensiones filosóficas hemos de tratar de estas cosas en conformidad con su verdad, pero en orden a la dialéctica solamente de acuerdo con la opinión general"69.

Aquí opone verdad a opinión, pero "tratar de estas cosas en conformidad con su verdad" lleva a los principios, premisas de la demostración, que se cree, según Aristóteles, en virtud de ninguna otra cosa que no sean ellos mismos, pero quien investiga los principios es la dialéctica que, sin embargo, en sus razonamientos, no parte de principios.

Pero en la Metafísica (Libro IV, Cap, 2, 1004b) dice Aristóteles que la dialéctica difiere de la filosofía "por el modo de su fuerza persuasiva". También dice: "La dialéctica pretende convencer y seducir en aquellas mismas cosas que la Filosofía pretendecỏnocerca de Letras

\section{"Jorge Puccinelli Converso"}

En los Tópicos (155b) dice Aristóteles que por lo que se refiere a la selección de sus fundamentos o puntos de apoyo "el problema es uno solo igualmente para el filósofo y para el dialéctico, pero la manera de estructurar sus puntos de vista y de disponer sus cuestiones corresponde tan solo al dialéctico, porque en todo problema de esta clase viene implicada una referencia a otra parte. No ocurre así con el filósofo, ni con el que está investigando algo por sí mismo...”.

Esta oposición se refiere nuevamente, “a que el filósofo está ansioso por asegurarse y por garantizar los axiomas como familiares y tan cercanos a la cuestión que lleva entre manos como es posible". Es decir, quiere garantizar la verdad de las premisas "porque estas son las bases sobre las que se construyen los razonamientos científicos". Es decir, estos se basan en premisas verdaderas

\footnotetext{
${ }^{63}$ Tópicos, Libro primero cap. 2, $101 \mathrm{~b}$.

${ }^{\circ 0}$ Tópicos $105 \mathrm{~b}$ (en Aristóteles Obras, traducción de Samaranch).
} 
y primarias, mientras que los razonamientos dialécticos parten de premisas probables; de opiniones generalmente admitidas.

También dice de la dialéctica: "Porque el arte de verificar un examen es una especie particular de la dialéctica (Argumentos sofísticos, cap. 11. 171a)"70. Dice ahí mismo: "El hombre, pues que mira los principios generales a la ley del caso particular es un dialéctico" (171a).

También considera la dialéctica "como un método de examen" (Ibid., 171a). La dialéctica es un arte de examen y este arte "no es un conocimiento de una materia definida" (Ibid., 172b), y en consecuencia "todo el mundo, aún la persona que nada tiene de científica, hace algún uso de la dialéctica y del arte del examen, pues todos, hasta cierto punto, intentan probar a los que profesan el saber".

Todos realizan la refutación "sin método, la misma tarea que la dialéctica realiza metódicamente; y el que lleva adelante un examen por medio de un arte de razonar es un dialéctico" (Argumentum sofistico, Cap. II, 176b, traducción de Samaranch). En esta obra, finalizando el capitulo sobre el examen y las refutaciones, dice Aristóteles:

"Estos son, pues, los modos de las refutaciones sofísticas. Es fácil ver que el investigarlos y el ser capaz de aplicarlos es tarea del dialéctico, pues el método de tratar las proposiciones constituye lactotalidadde s@estudio"(172b).

\section{"Jorge Puccinelli Converso»}

En los Tópicos (154a) sobre quien es dialéctico, escribe Aristóteles:

"Ya que es dialéctico, hablando en general, el que es un artista en el proponer cuestiones y en el ponerles objeciones".

La originalidad de Aristóteles es no tomar partido entre estas dos exigencias. "La una y la otra -dice Aubenque- son igualmente legítimas: no se puede esperar que Aristóteles desvalorizara la exigencia científica en un texto que es el prólogo a toda su obra biológica; es más extraño ver en este lugar, hacer el elogio de la cultura general, sobre todo si se piensa que los contemporáneos no podían no ver en este elogio de la cultura general, una rehabilitación de los sofistas y los retóricos..."71.

\footnotetext{
${ }^{70}$ Traducción de Samaranch en la edición Aguilar de las obras de Aristóteles.

"Op. cit., p. 282.
} 
La ciencia, es "exacta" como dice Aristóteles en muchos lugares (Metafísica A, 2, 982 a27; M, 3, 1078 a 10: De Anima, I, 1, 402 a 2; Top. II, 4, 111a8) pero tiene el inconveniente de no centrarse sino sobre "una naturaleza determi-nada"; de ignorar por consecuencia la relación de esta naturaleza con otras naturalezas y finalmente con la totalidad. La cultura tiene, la ventaja de ser general, pero tiene el inconveniente de no ser un saber. En la Política $(I I I, 11,1282$ a 6) opone los "hombres cultivados" a "aquellos que saben" como aquí la $\pi \alpha 1 \delta \varepsilon \imath \alpha$ o la $\varepsilon \pi \iota \sigma \tau \eta \mu \eta$.

El griego крıvєıv, señala Aubenque tiene un sentido negativo. Hablar de función crítica de la cultura significa que tiene el poder de condenar, no de decir. El juicio del hombre cultivado no se refiere a la verdad del discurso sino a la incompetencia de los otros, la cual reconoce y denuncia ${ }^{72}$.

En la Etica a Nicómaco I, 1, 1094 b23 ss. Traducción de J. Souihé modificada por Aubenque dice Aristóteles: "Es la marca de un hombre cultivado exigir solamente, para todo género de estudios, la precisión que comporta la naturaleza del sujeto. Sería tanabsurdo aceptar de un matemático razonamiento probables como reclamar de un retórico demostraciones"73.

El hombre cultivado es el que exige, para todo género de estudios la precisión que exige la naturaleza del sujeto. Un retórico es un hombre culto y no se le puede exigir demostraciỏne ésmás, esabsurdo, aś́como es absurdo aceptar razonamiento probablea un matemáticp. Converso"

Comentando este texto dice Aubenque: "Incapaz de hablar de otra manera que en general, tiene el privilegio de transmutar esta evidente insuficiencia en un poder que su ignorancia misma le confiere: la de confrontar el discurso científico, que es siempre parcial, con las exigencias del discurso humano en general." 74 .

"Universalidad, función crítica, carácter formal, apertura a la totalidad: tales son finalmente los rasgos que Aristóteles reconocía a la cultura general y que van a permitirle, al mismo tiempo que marcando netamente su oposición a la "ciencia de la cosa", de apreciar en ella, otra cosa que un vano parloteo. Se ve

\footnotetext{
${ }^{72}$ Cf. Aubenque op. cit., p 283.

${ }^{73}$ Op. cit., pp. 284-285.

${ }^{74}$ Ibid., p. 285.
} 
bien en qué sentido esta concepción de la cultura constituye una rehabilitación de la sofística y de la retórica contra los ataques platónicos..."75.

Aristóteles hace dos cosas: precisa rigurosamente lo que es el conocimiento científico; demuestra la imposibilidad de la ciencia suprema de los platónicos y la visión sinóptica es rehusada al sabio; así es asignada al hombre culto. Como dice Aubenque: "La función crítica es distinguida radicalmente por Aristóteles de la competencia; la ciencia suprema de los platónicos, de la cual Aristóteles ha demostrado por otro lado, la imposibilidad se ve aquí destronada en beneficio de una universalidad solamente formal; en fin el privilegio de la visión sinóptica es rehusada al sabio para ser restituida al hombre que ningún saber encierra en una relación particular al ser..."76.

Señala Aubenque que en el Organon encontramos de hecho el desarrollo y la justificación de la inversión paradojal sugerida por el texto de Parties des animaux.

"Lo que Aristóteles llama aquí "cultura general" aparece ahí bajo un nombre que nos ha resultado familiar: el de dialectica. Creemos haber suficientemente mostrado, por un estudio de sus orígenes que la dialéctica aristotélica era la heredera del ideal de universalidad de los sofistas y retóricos"77.

Esta ligazón es confirmada, al interior de la obra de Aristóteles "por el hecho de que la descripción que dá Afistôteles de las funciones de la cultura general coinciden exactamegrePconqainteoría deYardaléctica que desarrolló ampliamente en los Tópicos" ${ }^{\text {78 }}$.

Más aún: "Si retomamos, uno a uno, los caracteres de la cultura general que hemos distinguido antes, los veremos cada vez confirmados y precisados en la concepción aristotélica de la dialéctica..." ${ }^{\prime 79}$.

La universalidad que pertenece por definición a la cultura general, es el carácter esencial de la dialéctica y la función crítica "deriva, inmediatamente de la naturaleza interrogativa de la dialéctica"80.

\footnotetext{
${ }^{75}$ Ibid., p.285.

${ }^{76}$ Ibid., p. 285.

${ }^{77}$ P. Aubenque, op. cit. p. 286.

${ }^{78}$ Ibid., p. 286.

${ }^{79}$ Ibid., p. 286.

${ }^{80}$ Ibid., p. 286.
} 
En una nota (2) de la misma página escribe Aubenque: "A decir verdad, la crítica no es presentada por Aristóteles más que como una 'parte de la dialéctica' (Ref Soph. 8, 169b 25, 11, 171b4). Pero ella representa el único uso verdaderamente legitimo de la dialéctica."En los Tópicos (Libro Primero, Cap. 2 1016, traducción de P. Samaranch) escribe Aristóteles: "La dialéctica, en efecto, es un proceso de crítica en el que se halla el camino que lleva a los principios de toda investigación".

Dice Aubenque que la dialéctica refuta realmente (es entonces que es crítica); pero ella no demuestra más que en apariencia... ${ }^{81}$.

En los Tópicos escribe Aristóteles de la dialéctica: "Tiene también una utilidad ulterior en relación con las últimas bases de los principios que emplean las diversas creencias, pues es imposible someterlos a discusión a partir de los mismos principios propios de la ciencia particular de que se trata supuesto que los principios son lo anterior de todo lo demás; estos deben discutirse a la luz y en virtud de las opiniones generalmente sostenidas en las cuestiones particulares, y esta tarea corresponde propiamente, o más apropiadamente a la dialéctica..." ${ }^{82}$.

Luego viene lo que dice de la dialéctica como un proceso de crítica pero no cualquiera sino "en el que se hafla el camino que lleva a los principios de toda investigación”.

Escribe Aubenquie: "Ahơra bien hemosevisto que cuando la universalidad sobrepasa la unidad genériça salimos del-discurso científico, para entrar en un tipo de discurso que es precisamente el discurso dialéctico. La contrapartida de la negación aristotélica de una ciencia universal es la constatación de que no se puede hablar sino dialécticamente, es decir, negativamente, de la totalidad"83.

En relación con el carácter negativo de la dialéctica, según Aubenque, (en realidad la dialéctica no tiene sólo un carácter negativo en Aristóteles como se puede ver por lo que dice de la dialéctica como un proceso de crítica que conduce al camino que lleva a los principios de toda investigación), escribe: "Se notará a este propósito la formulación negativa del principio más universal de todos, el principio de contradicción: "Es imposible que el mismo atributo pertenezca y no pertenezca al mismo tiempo al mismo sujeto y bajo la misma

\footnotetext{
${ }^{81}$ Ibid., p. 286, nota 2.

${ }^{12}$ Tópicos $101 \mathrm{~b}$.

${ }^{13} \mathrm{Ibid}$., pp. 287, 288.
} 
relación" (G,3, 1005, b 19)". Este principio no tiene sino un sentido polémico: no aparece sino cuando se le niega, no se establece sino contra un adversario, real, ficticio. Aún si los negadores del principio de contradicción no hubieran históricamente existido, Aristóteles hubiera debido inventarlos por las necesidades de su justificación dialéctica del principio, la única que era posible teniendo en cuenta generalidad" $"$.

Dice Aristóteles: "Ningún método tendiente a manifestar la naturaleza de cualquier cosa que sea procede por interrogación (Ref. Soph 11, 17 a 15)"85.

Aquí asistimos al corazón mismo de la oposición entre actitud científica y actitud dialéctica. El Sabio demuestra las proposiciones, el dialéctico plantea los problemas que en apariencia, no difieren de las proposiciones que por su forma interrogativa, "pero que, en realidad, prohiben igualmente al cuestionante que al respondiente justificar, el uno, los términos de la alternativa, y al otro la elección de uno de los términos..."86.

El saber no puede progresar seguramente sino por la demostración, no por el diálogo. Lo que le falta a la dialéctica, según Aristóteles y cuya ausencia es responsable de su "impotencia", es la mediación, la mediación que en el silogismo demostrativo es aportada por el têrmino medio; es decir, por la esencia ${ }^{87}$. La dialéctica es pues, según Aristóteles, "una manera de pensar, o más aún de hablar que se mueve másallá de das esencias y espor tanto desprovisto de todo punto de apoyo real que le permita ayanzar. Sin embargo, en un texto donde resume el aporte de la investigación socrática, Aristóteles parece considerar, no como una desviación, sino como el signo de un progreso, que la dialéctica haya podido, en un cierto momento liberarse de la consideración de la esencia. En tiempos de Sócrates, escribe, "La fuerza dialéctica no era tal que se pudiera considerar los contrarios mismo independientemente de la esencia"88.

La dialéctica representa el orden de la investigación. Parece haber una oposición y un parentesco entre la dialéctica y la teoría del $\operatorname{ser}^{89}$.

\footnotetext{
${ }^{84}$ Ibid., p. 288 , nota 1.

${ }^{\text {ns }}$ Atado por Aubenque, op. cit., p. 290.

${ }^{86}$ Ibid., p. 290.

${ }^{87}$ Cf. Aubenque op. cit. pp. 292.293.

s* Aubenque, op. cit. p. 293.

${ }^{89}$ Ibid., p. 295.
} 
Los exégetas, señala Aubenque se han centrado en la oposición por su preocupación por oponer Aristóteles a Platón: "Ellos han sido cogidos por el hecho de que, del uno al otro, la dialéctica ha pasado del rango de ciencia al de simple lógica de lo verosímil, devenida pariente pobre de una analítica que sólo puede proporcionar el canon de un saber acabado" 90 .

Hamelin en su Sistema de Aristóteles (pp. 230-235) "ha puesto bien en relieve esta desvalorización aristotélica de la dialéctica" escribe Aubenque que no ve bien claro, pues no hay una desvalorización de la dialéctica aunque hay textos que hemos visto y que aparentemente la descalifican y desvalorizan frente a la ciencia y frente a la filosofía, pero hemos visto también que, o son contradictorios o son aparentemente desvalorativos, como ha mostrado el mismo Aubenque, quien ahora escribe: "Hamelin por ejemplo ha puesto bien de relieve esta desvalorización aristotélica de la dialéctica y Aristóteles, recuerda él, ha colocado a la dialéctica del lado de la opinión y la ha radical y definitivamente separado de la ciencia (p. 235), lo que vendría a afirmar que, para Aristóteles, "no hay nada en común entre la investigación de la verdad y la dialéctica"91 (p. 230).

La dialéctica pues un arte infra-científico y con más fuerte razón, ya que Aristóteles mismo, escribe Aubenque, designa a la filosofía como "la más alta de las ciencias", un arte infra-filosófico ${ }^{92}$.

\section{Biblioteca de Letras}

Sin embargo, Hamelin admitiráque la dialéctiç "participa sin embargo" de la verdad, porque se refiere a lo verosímil y porque permite el razonar formalmente justo: en este sentido puede igualmente ser considerada como un auxiliar de la ciencia, a la cual contribuye a establecer los principios. Pero esta contribución misma no debe ser sobrestimada. Contra Zeller, Hamelin estima que, en el establecimiento de los principios, la dialéctica no juega sino un papel negativo: "A propósito de cada principio, ella nos enseña sobre todo donde no se les puede buscar" (Ibid., p. 235); ella no hace sino desbozar el terreno para la intuición que permanece como el único fundamento de la demostración y, por ello, de la ciencia. La dialéctica no jugaría pues otro papel que el de una ayudante de, podríamos decir, pedagógico para los espíritus insuficientemente intuitivos..."93.

\footnotetext{
${ }^{90}$ Ibid., p. 295.

1 Ibid., pp. 295-296.

${ }^{92}$ Cf. op. pp 295-296.

${ }^{93}$ Ibid., p. 296.
} 
Si la dialéctica, según esto, no hace sino preparar el camino para la intuición que permanece como el único fundamento de la demostración, y por ello, de la ciencia, entonces la dialéctica cumpliría un fin "pedagógico" de ayudante para los espíritus insuficientemente intuitivos, y en este sentido el filósofo no necesitaría de la dialéctica. "Si se admite -escribe Aubenque-que de todos los hombres, el filósofo es el que tiene lo más en relación con la intuición, se admitirá también que es el que se pasa mejor sin la dialéctica, más aún, que en tanto filósofo, escapa completamente a las limitaciones que harían necesario el uso de la dialéctica" ${ }^{\text {"94. }}$.

Volveremos sobre la relación entre dialéctica e intuición.

Por otro lado los intérpretes han buscado la relación que podría unir "la especulación lógica de Aristóteles a su especulación metafísica" "95. Este lugar ha sido investigado en la equivalencia que Aristóteles establece algunas veces, dice Aubenque entre la noción física y metafísica de causa y la noción lógica de término medio; una y otra designan dos aspectos de una realidad más fundamental: la de la esencia. El término medio es causa en el silogismo.

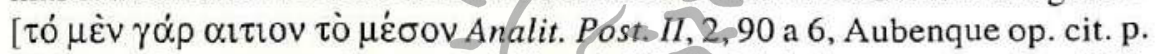
296, nota 5] porque es la esencia [cf. m 4, 1078 b 24 Aubenque op. cit. p. 296, nota 6] y que la esencia es lo que da razón de los atributos..."96. E. Weil menciona esta interpretación para refutarla ${ }^{97}$

Estas interpretaciopęs y lå de b.RobindSur lat conception aristotélicienne de la causolité) tiende en lo que concierne a este problema a lo siguiente, según Aubenque: "el ideal de la metafísica aristotélica sería un ideal analítico, es decir, deductivo; su punto de partida sería la intuición; su instrumento el silogismo, el silogismo no siendo él mismo sino el despliegue de la esencia en el discurso humano. Si es verdad que la esencia no nos enseña jamás la esencia de cualquier cosa que sea, que su especulación se mueve "independientemente de la esencia"; que no se endurece a ninguna esencia determinada, menos aún sobre la más alta, se ve cómo se encontraría así justificada la incompatibilidad de la dialéctica y de la filosofía"98.

Pero toda esta interpretación peyorativa de la dialéctica aristotélica y de sus relaciones con la filosofía del ser "ha podido ser influida-dice Aubenque-

\footnotetext{
${ }^{94}$ Ibid., p. 296.

${ }^{95}$ Ibid., p. 296.

${ }^{90}$ Ibid., p. 296.

${ }^{97}$ Aubenque, op. cit., p. 296, nota 4, remite a la place de la logique dares de pensie aristotelicienne, loc. cit., p. 1314.

${ }^{95}$ Ibid., p. 297.
} 
en los autores de fin del siglo XIV y de comienzo del siglo XX, por un idealismo que veía en la ciencia el único lugar concebible de la verdad"99.

En una nota (3), escribe Aubenque: "Es característico a este respecto que Hamelin concluye de la oposición aristotélica de la dialéctica y la ciencia, que para Aristóteles, "no hay nada en común entre la investigación de la verdad y la dialéctica"(loc cit.). Robin, igualmente, no puede suponer que Aristóteles haya traicionado el ideal matemático de su maestro al punto de haber querido hacer descender la filosofía al nivel infra-científico de la dialéctica. Brunschvicg admitía de buena gana que la metafísica de Aristóteles es dialéctica, pero en el sentido en que, según Aristóteles mismo las especulaciones son "verbales y vacías". Ninguno de estos autores podía, en razón de sus proposiciones filosóficas propias, hacer justicia a la dialéctica aristotélica y a fortiori acordarle un lugar eminente en la construcción filosófica de Aristóteles. Inversamente, los autores alemanes, a menudo inspirados por el hegelianismo, como Michelet o Zeller, insisten sobre el papel positivo de la dialéctica, pero la entienden, de manera anacrónica, como una lógica de la contradicción y de la superación, superior, por este hecho, a la analítica, interpretada por Hegel como "lógica del entendimiento", "historia natural del pensamiento finito". En realidad, la dialéctica, tal como la entiende Aristóteles, no amerita ni este exceso de honor ni esta indignidad. Es a un autor poco sospechoso de tomar partidos filosóficos, Ch. Thurot, que corresponde el mérito de haber evaluado con la mayor exactitud el papel de la dialéctica epla metafísica de Aristóteles (cf. $\mathrm{Ch}$. Thurot, Études, sur Ar: Politique, dialectique , thetórique, 1860 , especialmente p. 132 ss.")100.

La interpretación de estos autores parten de sus presuposiciones filosóficas propias lo que no les permite evaluar con justicia la dialéctica aristotélica, dice Aubenque. Más exacto sería decir, no que no le hacen justicia -o que no les permite evaluar con justicia la dialéctica aristotélica- sino que no son capaces de tener una idea exacta de la dialéctica de Aristóteles. El problema es que hay textos que oponen dialéctica y filosofía, como hemos visto. Hay un texto solamente que trata expresamente de las relaciones de la dialéctica y de la especulación general sobre el ser, "y este texto es tan confuso -escribe Aubenqueque no justifica solamente las interpretaciones divergentes de los comentadores, sino que parece traducir una perplejidad real de Aristóteles mismo. En este texto que encontramos en el libro I de la Metafísica, Aristóteles, explícitamente

\footnotetext{
${ }^{99}$ Ibid., p. 297.

${ }^{100}$ Ibid., p. 297 nota 3.
} 
preocupado en distinguir e igualmente oponer filosofía y dialéctica, comienza nada menos por reconocer la identidad de sus dominios: "El género de realidades en que se mueven la sofística y la dialéctica es el mismo que para la filosofía, pero esta difiere de la dialéctica por la manera de usar de la facultad, y de la sofística por la elección del género de vida..."101 (G, 2, 1004, b 22-25).

El dominio común a estas tres actividades fue sugerido un poco más antes: de trata de "todas las cosas" ( $\pi \varepsilon \rho i \dot{\alpha} \pi \dot{\alpha} \nu \tau \omega \nu)$, es decir del ser, puesto que este es "común a todas las cosas" 102 . (Ibid., 1004 b 20 referencia de Aubenque).

Hay identidad de dominio entre estas tres actividades pero "la identidad de dominio no excluye la diversidad de las actitudes y en primer lugar de las intenciones -escribe Aubenque-: la oposición, desde este punto de vista, entre sofística y filosofía es fácil de comprender y ha sido muchas veces precisada por Aristóteles: el sofista no busca sino su beneficio y no la verdad (Ref. Soph, 1, 165 a 22, 11, 17, b 287 Referencia bibliográfica de Aubenque). Es en otra parte, en la definición misma de la función dialéctíca y filosófica, donde es necesario buscar el fundamento de su distinción: "La dialéctica es una prueba relativa a lo

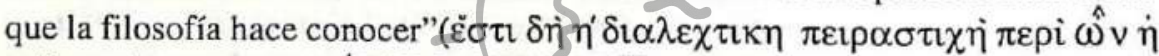
$\psi \iota \lambda о \sigma o \phi \iota \alpha \gamma \nu \omega \rho \iota \sigma \tau v \dot{\eta})(\mathrm{G}, 2,1004 \mathrm{~b} 25)^{103}$.

Con esto se han contentado los comentadores pensando que esta vez, la competencia del dialéctico y delefilósofose hat delimitado claramente en el texto. Los comentadorešcestán_general mientecsatisfecchos pues: “Aristóteles no vería en la dialéctica sino una prueba, en el sentido socrático del término, destinada a preparar o a confirmar, a los ojos de los hombres, y en primer lugar al filósofo mismo, la realidad del saber filosófico. Pero una doble cuestión se plantea aquí ¿En qué, la relación entre filosofía y dialéctica, que Aristóteles anuncia como privilegiada, en razón de la identidad de su dominio, se va a distinguir de la relación entre la dialéctica y las otras ciencias? Dicho de otro modo lo que Aristóteles decía aquí de la filosofía lo hubiera podido decir a propósito de cualquier otra ciencia particular: hemos visto en otra parte que Aristóteles asignaba, en efecto, a la dialéctica, y en primer lugar a la cultura general, esta función de examen y de crítica con respecto a todo saber particular. Pero esta consideración nos conduce a una segunda cuestión: ¿la filosofía es una ciencia particular? O

${ }^{101}$ Ibid., p. 298.

${ }^{102}$ Ibid., p. 298.

${ }^{103}$ Ibid., p. 298. Referencia bibliográfica de Aubenque. 
aún: ¿Cuál es este dominio del cual la filosofía sería el saber, que la filosofía no haría conocer?. Recordemos que este dominio es el ser en tanto tal, "común a todas las cosas"; esto responde a la cuestión suprimiéndola: no hay para Aristóteles objeto del cual la filosofía sería el saber, por esta razón que hemos ampliamente desarrollado, que toda ciencia se dirige a un género, que el ser "común a todas las cosas" no puede ser aprehendido en la unidad de un género y que no hay por lo tanto, en sentido estricto, "ciencia" que nos hiciera "conocer" el ser"104.

Esta cita tan larga presenta el comentario de Aubenque y su argumentación que nos parece decisiva sobre este punto de las relaciones entre dialéctica y filosofía. Claro está que se basa en su interpretación central sobre el problema de ser en Aristóteles.

En un texto de las Refutaciones Sofisticas (11, 172 a 12) Aristóteles, definiendo los caracteres de la argumentación dialéctica, "establece involuntariamente-escribe Aubenque-el carácter dialéctico de los argumentos sobre el ser en general: El argumento dialéctico no estálimitado a un género definido de cosas, no es demostrativo y no es tal que el argumento que se dirige a lo universal... El tema esencial de la especulación de Aristóteles sobre el ser ..."105.

¿Cuál es este tema esencial de la especulación de Aristóteles sobre el ser, según Aubenque? "Si el ser en general (Aristóteles no dice todavía el ser en tanto ser) no es un género, è̉onecesario entonces convenir que no se puede hablar sino dialécticamēntedelelser engenerab'1106 erso»

Si la filosofía lograra constituirse como ciencia según el tipo definido en los Analíticos, la oposición entre la dialéctica y la filosofía sería justificada, y sería similar a la que mantiene con toda ciencia particular, que es la de ser una propedeútica a este saber. Pero la filosofía se presenta como una ciencia universal, la dialéctica como un poder universal de examen y crítica. "Se podría pensar que, igual que la dialéctica es, cada vez, una propedeútica a cada saber particular, igualmente, considerada en su conjunto, ella es la propedeútica al saber universal. Pero hemos visto que el saber universal no lograba sobrepasar el nivel de una propedeútica, que la filosofía del ser es una ciencia "investigada" y que se exprese en esta investigación ella misma; brevemente, que estamos siempre en

\footnotetext{
${ }^{104}$ Ibid., p. 299.

${ }^{105}$ Ibid., p. 299 , nota 1.

${ }^{100}$ Ibid., p. 299, nota 1.
} 
camino hacía la totalidad. Desde entonces, lo que va a aproximar de hecho la dialéctica y la filosofía, no es solamente la identidad de sus dominios, sino también la identidad de sus pasos..."107.

La filosofía del ser se presenta como un conjunto de problemas y no de proposiciones; como dice Aubenque una "ciencia eternamente "buscada", de modo que la preparación dialéctica al saber deviene el sustituto del saber mismo"108.

De modo que el ideal "cognitivo" que diferenciaría a la filosofía de la dialéctica, no puede realizarse por la misma universalidad de la filosofía y así el texto de la Metafisica (Libro IV. "Confirma por el hecho, en el mismo momento en el que las pretende disociar, el parentesco de la ontología y la dialéctica"109.

Si la identidad de los procedimientos de pensamiento la dialéctica y la ontología, debería confirmarse por análisis minucioso de los procedimientos puestos en obra en la Metafisica y eso es un gran trabajo, se podría decir que el método aporético de las exposiciones introductorias de Aristóteles -siendo la aporía y la diaporía (desarrollo de dos argumentos pro y en contra cuya "igualdad" determina el estado de aporía) procedimientos dialécticos (Top VI, $6,145 \mathrm{~b}, 1,17)$; siendo la aporía definida por el mismo Aristóteles (Top VIII, 11,162 a 17) como "razonamiento dialéctico de contradicción"- y otros procedimientos que mueștra ènsutratado sobrela dialéctica; los Tópicos muestra esa identidad y que el grap fillósgfoe Aristóteles es dialéctico en su investigación ontológica en donde no hace uso de la demostración silogística. Como escribe Aubenque: "Es necesario mostrar que, si el silogismo está prácticamente ausente de la Metafísica, se encuentra ahí, por el contrario todos los procedimientos descritos por los Tópicos o las Refutaciones sofísticas: la refutación, la división (bajo la forma propiamente aristotélica de la distinción de sentido), la inducción, la analogía, etc. Citamos solamente aquí de memoria, el establecimiento del principio de contradicción por la refutación de sus negadores, la distinción de los sentidos del ser, la determinación puramente analógica de los principios enfocados en su unidad; de un manera general, el carácter diaporético de las exposiciones "introductoras" que tienden a confundirse aquí con la Metafísica en su conjunto, y casi por doquier este tono polémico que siguiendo las justas

107 Ibid., p. 299-300.

10 A Aubenque, op. cit., p. 300.

${ }^{109}$ Aubenque, op. cit., p. 300. 
expresiones de Charles Thurot revelan mas "el diálogo de la disputa" que el monólogo de la ciencia" ${ }^{110}$.

¿Quiere decir que ontología y dialéctica se confunden?. Es cierto que la intención filosófica es cognoscitiva - o "cognitiva". Es un instrumento universal de examen y su esencia es plantear las cuestiones mas que resolverlas y es indiferente al contenido. La filosofía no puede permanecer indiferente al contenido.

Aristóteles, dice Aubenque no ha querido constituir una ontología dialéctica y su ontología no parecerá jamás dialéctica que a un observador: este observador fue el mismo Aristóteles.

Por qué la palabra sobre el ser es dialéctica y no científica, la realidad de la ontología es dialéctica ${ }^{111}$.

Cesar Augusto Viano en su artículo "La dialéctica en Aristóteles"112 presenta un estudio bastante detallado de los procedimientos dialécticos expuestos en los Tópicos pero considera que en la cultura griega "la posición aristotélica constituye la ruptura abierta con la tradición socrática" 113 y también afirma -a diferencia de Aubenque, cuya posición compartimos en lo fundamental-que la búsqueda aristotélica "se coloca en este sentido en el interior de la dialéctica platónica y desarrolla uno de sus aspectos particulares en cuanto enseña a servirse de las formulaciones más ventajosas de una tesis y a recoger los puntos débiles en las formulaciones de ta discusión.

\section{"Jorge Puccinelli Converso»}

Esto último podría decirlo de la sofística, más aún teniendo en cuenta que Aristóteles no menciona a Platón como su predecesor en este asunto: Viano continua escribiendo: "Por ello desde un principio Aristóteles no presenta su propia búsqueda como una forma radicalmente distinta de la platónica de estudiar la dialéctica, ni se propone ofrecer una alternativa a las posiciones de su maestro. La investigación aristotélica se configura como un trabajo interno de la dialéctica platónica, o, remontándonos todavía más como una típica referencia controvérsica a la filosofía socrática"115.

\footnotetext{
110 Ibid., pp. 300-301.

"' Cf. Aubenque, op, cit., p. 302.

112 Abbagnano, Bobbio Chioldi, y otros La evolución de la dialéctica, Ediciones Martinez Roca, Barcelona 1971.

${ }^{113}$ Op. cit., p. 73.

114 Ibid., p. 50.

"1s Ibid., p. 50.
} 
Ahora bien esta exposición muestra que esas afirmaciones son falsas o inexactas. Según este auțor "Para Aristóteles, abandonando el planteamiento platónico, el filósofo y el dialéctico son dos figuras radicalmente diversas..." Según Viano la discusión, una vez descubiertos los principios científicos no tiene ningún valor ${ }^{117}$.

Si bien Viano menciona las funciones de la dialéctica y entre ellas la "función de búsqueda que lleva a la ciencia" y que la dialéctica se presenta "como arte de ordenar las opiniones" no repara en la importancia de la dialéctica para Aristóteles, debido a su afán por relacionar a Aristóteles "con su maestro" y con Sócrates.

"La dialéctica aristotélica, en su formulación más madura es la técnica de confrontar una tesis deduciendo su contradictorio de premisas fundadas en la opinión, es decir, la técnica de confrontar una afirmación cualquiera con un grupo de creencias más o menos organizado"118.

Cita: Elencos Sofísticos, 2, 165b, 2-4 y concluye: "Difícilmente encontraríamos otro teorema que diferencie tan netamente la concepción aristotélica de la dialéctica de la platónica. Mientras para Platón la dialéctica tiene la doble misión de liberar de la opinión y enseñar la forma de utilizar los conocimientos particulares, en cambio para Aristóteles la dialéctica queda confinada al mundo de la opinión, con una misiót pręliminan en sus relaciones con las ciencias, pero destinada a desaparecer cuando éstas brotan..."

Viano se basa en la concepción aristotélica de la ciencia que ve en forma lineal, superficial y no dialéctica y profundamente.

"El punto de ruptura está sin duda precisamente en la concepción de la ciencia, que para Aristóteles es enunciación unívoca y necesaria de la realidad y no búsqueda y tanteo; y como consecuencia de este planteamiento quedan confinados al mundo de la opinión, la discusión, todo el mundo socrático de la duda y la réplica..."120.

\footnotetext{
${ }^{116}$ Tbid., p. 65.

117 Ibid., p. 67.

11" Tbid., p. 73.

${ }^{119}$ Ibid., p. 73.

${ }^{120}$ Ibid., p. 73.
} 
Dice Viano que para Platón la dialéctica era el medio de acceder al ser y que Aristóteles niega al método dialéctico este carácter principal. "Con él no se accede al ser, porque el ser únicamente es asible por medio del lenguaje apofántico; por consiguiente dado que su función se limita al mundo de las creencias constituidas no es utilizable para problemas fundamentales..."121.

Esto no es cierto, como muestra el presente trabajo.

Completando su visión negativa de la dialéctica aristotélica y su incomprensión, dice Viano que el verdadero razonamiento dialéctico se presenta "como imitación de la ciencia: esta relación imitativa se funda sobre la estructura lógica común al razonamiento apodíctico y al dialéctico. Ambos se sirven del silogismo y difieren sólo en el valor de sus premisas"122.

A pesar de esto último que dice y que le permitiría analizar la diferencia en forma más de acuerdo a lo que dice Aristóteles en su tratado de la dialéctica, este autor saca otras consecuencias, siempre con la obsesión de destacar además, la diferencia con la dialéctica en Platón.

Por último escribe:

"Con esta concepción de la dialéctica, Aristóteles echaba por tierra uno de los puntos con los quẹflatỏn estuvo más enc̄ariñado: el vínculo existente entre verdad y búsqueda entre discusión y conocimiento entre demostración y revisión. Para Aristóteles la dialéctica es una lógica menor que mora en los campos de la búsqueda y de la discusión, campos en los que son posibles las conexiones, pero en los que no se alcanzan nunca ni el conocimiento ni la verdad, ni la demostración. Queda siempre limitada a una lógica de lo probable, es decir, una lógica que en último análisis recurre a las creencias constituidas"123.

Es cierto que es una lógica de lo probable pero esto no quiere decir que es una lógica que en último análisis "recurre a las creencias constituidas".

Las premisas probables, no son "en último análisis" las creencias constituidas. Aristóteles dice que son las opiniones de todos los hombres de la

\footnotetext{
121 Ibid., p. 74.

122 Ibid., p. 74.

${ }^{123}$ Ibid., pp. 74-75.
} 
mayoría, de los más sabios; en última instancia las opiniones de los filósofos. No "recurre" tampoco a las creencias constituidas. El punto de vista de Viano revela, en primer análisis, incomprensión. Este trabajo lo muestra, aunque no constituye, ni en primera, ni en última instancia, una crítica a su posición.

En una bella página escribe Aubenque: "El pensamiento estabilizante, es decir, la ciencia, es evidentemente menos apto, aún cuando no se comprende sino al interior del movimiento, a captar lo que hay de moviente en el movimiento mismo. La ciencia separa lo necesario, es decir lo que no puede ser de otra manera, sobre un fondo de contingencia, es decir, de lo que puede ser de otro modo. Pero si la contingencia no puede ser jamás borrada de su horizonte, la ciencia es menos atenta al horizonte mismo que a los modos de estabilidad que ella descubre ahí. No es pues a ella, sino a otra disciplina del alma, a otro modo estabilidad que ella descubre ahí. No es pues a ella, sino a otra disciplina del alma, a otro de discurso, que será necesario recurrir para pensar no más tal o cual dominio al interior de este horizonte, sino este horizonte mismo..."124.

Puesto que en el mundo sublunar/la necesidad nace sobre un fondo de contingencia, "es a un pensamiento más abierto, a un discurso más general que el pensamiento y el discurso de lo necesario, que le pertenecerá pensar el mundo sublunar como horizonte de los eventos que de ahí se producen, es decir, como mundo contingente. Nosotros hemos ya encontrado y descrito ampliamente más antes este pensamiento abierto a lo indeterminado, este discurso que se mueve más allá de todos los generos: es a lo que Áristóteles ha dado el nombre de dialéctica"125.

Afirma Aubenque que no puede ser sin significación constatar el mismo balanciamiento en la actitud de Aristóteles en relación a la dialéctica como en relación al movimiento, el tiempo y la contingencia, y que la dialéctica, en relación con la ciencia "ella encuentra en lo mismo que parecía descalificarla-su demasiado grande generalidad, su inestabilidad, su incertidumbre- la ocasión de afirmar una superioridad imprevista..."126.

Puede parecer exagerado pero Aubenque llega a afirmar que el hombre, "está, en un sentido, condenado a pensar el ser dialécticamente, porque está

\footnotetext{
124 Ibid., p. 494.

125 Tbid., pp. 494-495.

${ }^{126}$ Ibid., p. 495.
} 
privado de la intuición de un origen del cual está irremediablemente separado y de una totalidad de la cual es un fragmento..."127.

Puede parecer retórico, o dialéctico o sofístico aquí, "pero se encuentra que el carácter dialéctico de la marcha abraza aquí lo que hay de inacabado en un ser en tanto ser que no es el mismo sino el índice de una unidad imposible. El método dialéctico -escribe Aubenque- nos dice Aristóteles, no nos permite jamás aprehender jamás cualquier cosa que sea"128 (Ref. Soph. 11, 172 a 15).

Esta cita de Aristóteles bastaría para descalificar la argumentación de Aubenque pero este pregunta (retóricamente): ¿Pero de que serviría una intuición de las esencias que, separadas de ellas mismas por el movimiento, siempre en potencia de ser otra cosa, no son jamás lo que son?"'129.

A favor de su punto de vista. Aubenque menciona un texto en donde Aristóteles dice que hay dos clases de seres: los seres primeros y por sí, es decir, seres inmóviles y simples que son su propia quididad puesto que no son otra cosa que esencia y puesto que la esencia es para él la quididad (Z. 6, 1032 a 5, 1031 b 32).

Pero lo que caracteriza a las quasi-esencias del mundo sublunar por oposición a las esencias simples e inmutables, es que son separadas de ellas mismas; pero lo que las aproxima a las primetas \& autoriza llamarlas también esencias, es que pueden coincidir con ellas mismas, si no inmediatamente, al menos por un rodeo..." ${ }^{130}$.

Se necesita pues una mediación. Estos intermediarios en el saber teórico son la demostración y la dialéctica. Pero la demostración es mediación para nosotros. Todo el movimiento de la demostración no tiene por fin sino manifestar la relación exterior entre un sujeto y un predicado ${ }^{131}$.

"La dialéctica por el contrario -escribe Aubenque-no nos encamina hacía la intuición de una esencia, que haría desde entonces inútil la investigación de una mediación. Ella no es mediación hacia la esencia, sino que es el sustituto de

\footnotetext{
${ }^{127}$ Ibid., p. 495.

128 Ibid., p. 495.

129 Tbid., p. 495.

${ }^{130}$ Ibid., p. 495.

${ }^{131}$ Ibid., p. 496.
} 
la unidad esencial, ahí donde esta unidad es inencontrable... bien que inferior en valor a la demostración y a la intuición, es sin embargo cada vez en los casos extremos, aquellos en que la demostración y la intuición están ausentes. Así es, lo hemos visto, para la intuición de los principios; así es cuando se trata de manifestar, entre el ser sensible y su quididad, una unidad que es propiamente ontológica, es decir que no se atiende sino al discurso que tenemos sobre ella y que se derrumbaría sin él..."132.

Esto podría parecer contradecir la función que Aristóteles asigna a las intuición de ser la facultad de los extremos y la que asigna al discurso de ser la facultad de los intermediarios ( $\mu \varepsilon \tau \alpha \xi \dot{v})$; pero ahí donde la intuición falla, es menester que el discurso supla a su silencio. ${ }^{133}$

Es porque la dialéctica es la facultad de los intermediarios que puede suplir el silencio delante de los extremos. El fracaso de la intuición es la realidad de la dialéctica.

"La dialéctica no tiene sentido sino si-aspira a su propia supresión, es decir, a la intuición.." ${ }^{134}$.

"La investigación de la filosofía, dicho de otro modo, la dialéctica deviene filosofía de la investigación..."135,

\section{Biblioteca de Letras}

Podríamos terminar coñle siguiente que escribe Aubenque:

"Pero la dialéctica que es el aspecto teórico de la mediación, no es el único aspecto, puesto que la filosofía de Aristóteles no es solamente una filosofía teórica. Ella no olvida que es también una filosofía práctica y poética, manifestando por ello que el saber o la investigación del saber no constituye el único modo de relación del hombre con el ser. Estos otros dos aspectos de la existencia humana, que una filosofía total debería también considerar, Aristóteles los ha denominado $\pi \rho \hat{\alpha} \xi \xi \varsigma$, por la cual designa la acción inmanente, principalmente

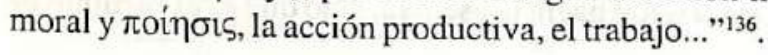

\footnotetext{
${ }^{132}$ Ibid., p. 497.

${ }^{13}$ Ibid., p. 497.

${ }^{134}$ Cf. Aubenque, op. cit., p. 497.

135 Ibid., p. 504.

${ }^{136}$ Ibid., p. 504.
} 
Por otro lado, Carlos Augusto Viano hablando sobre el mecanismo de la discusión dialéctica dice que los dos casos límite en que no se origina discusión dialéctica lo constituye lo que nadie aceptaría (paradoja) y lo que todos admiten ${ }^{137}$.

Siempre con su actitud peyorativa hacia la dialéctica en Aristóteles, escribe: "Esta vegeta en las zonas de consensos, de opiniones suficientemente elevadas, relativamente coherentes, fundados sobre lo habitual de la mayoría o sobre el parecer de los competentes y siempre depende de las condiciones subjetivas de los interlocutores: del valor que conceden a las opiniones corrientes y de lo amplio del terreno por el que se extienden las preguntas. Sus límites son la certeza absoluta y la total incredulidad" 138 .

Fuera de expresiones como "vegeta" y "opiniones corrientes" y "condiciones subjetivas", Viano a pesar de que quiere con ellos desvalorizar a la dialéctica aristotélica, sin querer define su actualídad pues afirma que la dialéctica tiene su acción en las zonas de consensos, de opiniones suficientemente elevadas relativamente coherentes, fundadas sobre lo habitual de la mayoría o sobre el parecer de los competentes y que depende de las condiciones subjetivas de los interlocutores y del valor que conceden a las opiniones y de lo amplio del terreno en que extienden las preguntas. Sus límites son la certeza absoluta pues con esa actitud no puede haber diálogo ni dialéctica, y la total incredulidad, o más precisamente el escepticismo bel nihilismo para el cuălna hay discurso, ni discusión.

\section{"Jorge Puccinelli Converso»}

${ }^{137}$ Carlos August Viano, op, cit., p. 71.

138 Ibid., p. 71. 